\begin{tabular}{|l|l|}
\hline 2. To: (Receiving Organization) & 3. From: (Originating organization) \\
Packaging Engineering & Packaging Engineering \\
\hline 5. Proj./Prog./Dept./Div.: & 6. Design Authority/ Design Agent/Cog. \\
$03 E 00$ & J.Egr.: Mercado \\
\hline
\end{tabular}

8. Originator Remarks:

The attached document is being submitted for approval and release.

11. Receiver Remarks:
11A. Design Baseline Document?

[] Yes
[X] No

4. Related EDT No.:

NA

7. Purchase Order No.:

NA

9. Equip./Component No.:

NA

10. System/Bldg./Facility: NA

12. Major Assm. Dwg. No.: NA

13. Permit/Permit Application No.: NA

14. Required Response Date: NA

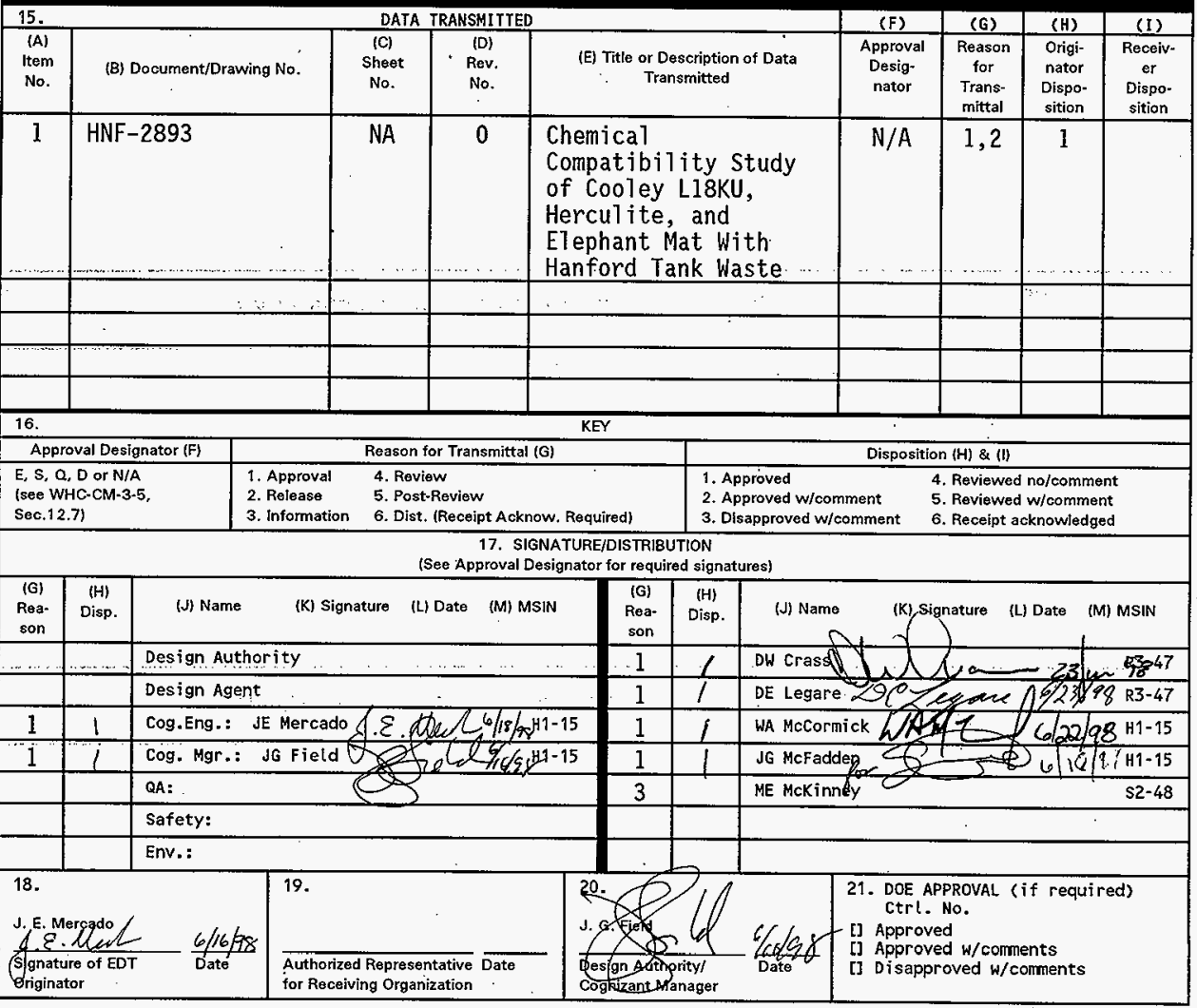




\section{Chemical Compatibility Study of Cooley L18KU, Herculite, and Elephant Mat With Hanford Tank Waste}

\section{J. E. Mercado}

Waste Management Federal Services, Inc., Northwest Operations Rich 7 and, Washington 99352

for Fluor Daniel Hanford, Inc.

U.S. Department of Energy Contract DE-AC06-96RL13200

EDT/ECN: EDT 622367 UC: 513

Org Code: 03E00 Charge Code: D6309

B\&R Code: EW3130010 Total Pages: il

Key Words: LLCE, flexible receiver bag

Abstract: An independent chemical compatibility review of various wrapping and absorbent/padding materials was conducted to evaluate resistance to chemicals and constituents present in liquid waste from the Hanford underground tanks. These materials will be used to wrap long-length contaminated equipment when such equipment is removed from the tanks and prepared for transportation and subsequent disposal or storage. The materials studied were Cooley L18KU, Herculite, and Elephant Mat. The study concludes that these materials are appropriate for use in this application.

TRADEMARK DISCLAIMER. Reference herein to any specific commercial product, process, or service by trade name, trademark, manufacturer, or otherwise, does not necessarily constitute or imply its endorsement, recommendation, or favoring by the United States Government or any agency thereof or its contractors or subcontractors.

Printed in the United States of America. To obtain copies of this document, contact: WHC/BCS Document Control Services, P.0. Box 1970, Mailstop H6-08, Richland WA 99352 , Phope (509) 322-2420: Fax (509) 376-4989.
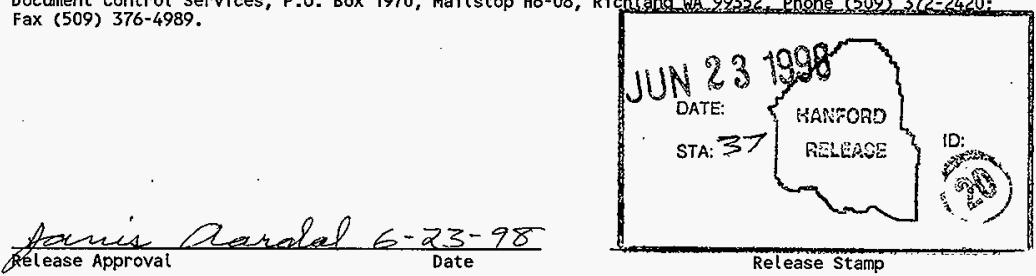

\section{Approved for Public Release}


HNF-2893, Rev. 0

\section{CONTENTS}

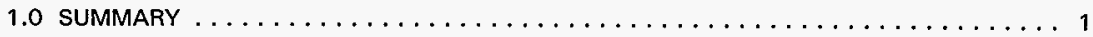

2.0 BACKGROUND $\ldots \ldots \ldots \ldots \ldots \ldots \ldots \ldots \ldots \ldots \ldots \ldots \ldots \ldots \ldots$

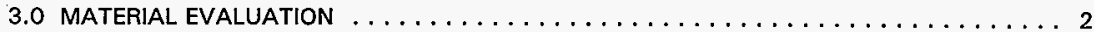

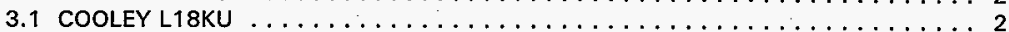

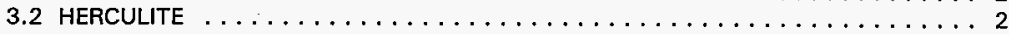

3.3 ELEPHANT MAT $\ldots \ldots \ldots \ldots \ldots \ldots \ldots \ldots \ldots \ldots \ldots \ldots \ldots$

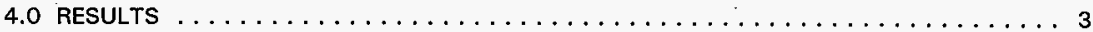

5.0 CONCLUSIONS AND RECOMMENDATIONS $\ldots \ldots \ldots \ldots \ldots \ldots \ldots$

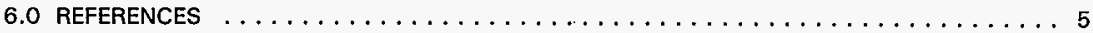

APPENDIX: HERCULITE PRODUCTS, INC., CHEMICAL RESISTANCE GUIDE $\ldots \ldots \ldots \ldots$ 
HNF-2893, Rev. 0

\section{CHEMICAL COMPATIBILITY STUDY OF COOLEY L18KU, HERCULITE, AND ELEPHANT MAT WITH HANFORD TANK WASTE}

\subsection{SUMMARY}

An independent chemical compatibility review of various wrapping and absorbent/padding materials, referred to herein as the flexible receiver bag material, was conducted to evaluate resistance to the chemicals and constituents present in liquid waste from the Hanford underground tanks. These materials will be used to wrap long-length contaminated equipment (LLCE) when such equipment is removed from the tanks and prepared for transportation and subsequent disposal or storage. The materials studied were Cooley L18KU; Herculite la trademark of Herculite Products, Inc.); and Elephant Mat (a trademark of New Pig Corporation). The study concludes that these materials are appropriate for use in this application. Several assumptions are necessary to support this conclusion.

- The tank waste will not be sustained at an elevated temperature $\left(>49^{\circ} \mathrm{C}\left[120^{\circ} \mathrm{FI}\right)\right.$ during the process of removing the LLCE.

- The LLCE will be pressure washed and allowed to drain in a vertical position to remove the majority of waste on the exterior before being lowered and placed in the disposal/storage container.

- Because the LLCE is placed on a skid when positioned in the LLCE container, the flexible receiver bag is not subjected to excessive abrasion during the operation.

- The flexible receiver bag is no longer required to provide the primary containment boundary after packaging in the LLCE container.

\subsection{BACKGROUND}

The LLCE includes instrument trees, piping, and pumps, which have been placed in the tanks over many years. During the process of removing the LLCE from a tank, the LLCE will be pressure-washed; the concentrations of available reactants on the exterior of the LLCE is expected to be low. However, it is may not be possible remove all of the material from the LLCE because of the nature of the equipment, so some liquid may leak out in handling or storage. Because of the washing operation, drain leakage is only expected when the LLCE is lowered to a horizontal position. It is assumed that the tank waste will be at ambient or near ambient temperatures during the equipment removal and subsequent operations.

Three polymer textiles have been selected as candidates for wrapping LLCE for transportation and storage. The brand names of the materials are Cooley L18KU, Herculite, and Elephant Mat. In the intended application, the Elephant Mat will be used as an absorbent padding inside the flexible receiver bag constructed of Cooley L18KU or Herculite. The polymers used in the construction of the three products include nylon, polyester, polyvinylchloride (PVC), and polypropylene.

This study supplements the chemical compatibility evaluation that was performed for the high-density polyethylene LLCE container (Veith 1996). 
HNF-2893, Rev. 0

\subsection{MATERIAL EVALUATION}

The chemical properties of each material were evaluated with respect to manufacturer data and other sources for material properties.

\subsection{COOLEY L18KU}

\section{Cooley}

L18KU is a PVC-coated membrane. The base fiber is nylon and polyester, and the coating is PVC.(Cooley 1995).

Additional data on PVC, nylon, and polyester were obtained from the following various sources.

\section{Flinn and Troian}

PVC-Resistant to acids and alkalies; attacked by organic solvents.

Polyester-Attacked by acids, alkalies, and organic solvents (Flinn and Trojan 1981).

\section{Merck}

Nylon-Soluble in phenol, cresols, xylenol, and formic acid. Insoluble in alcohols, esters, ketones, and hydrocarbons (Merck \& Co. 1989).

\section{RyanHerco}

PVC-Resistant to most solutions of acids, alkalies, and salts and to organic compounds miscible with water. Not resistant to aromatic and chlorinated hydrocarbons.

Specifically, PVC is unsuitable for acetone, benzene, carbon tetrachloride, cyclohexanol, dibutyl phthalate, ethyl acetate, ethylene dichloride, concentrated sulphuric acid, toluene, trichloroethylene, and xylene (RyanHerco 1997).

\section{CRC}

PVC-Poor resistance to ketones, esters, oils, and aliphatic and aromatic hydrocarbons (CRC 1981).

\subsection{HERCULITE}

Herculite Products, Inc.

This material is described as a laminated vinyl-synthetic fabric. The precise composition is proprietary. Resistant to inorganic salts, alkalies, and weak acids. The fabric is resistant to strong acids, alcohols, aliphatic hydrocarbons, and oils for short periods depending on concentrations, temperatures, and exposure times. The fabrics are not recommended for use with ketones and esters (Herculite 1997). Herculite Products, Inc., compatibility table is included in the appendix. 
HNF-2893, Rev. 0

\subsection{ELEPHANT MAT}

New Pig Corporation

Elephant Mat is over $95 \%$ polypropylene with polyester stitching. Susceptible to strong oxidizing agents. May be affected by acids and bases (Pig MSDS).

Additional data on polypropylene was obtained from the following various sources.

Merck

Polypropylene-Practically insoluble in cold organic solvents . . . resistant to acids, alkalies; attacked by strong oxidizers, e.g., hydrogen peroxide. (Merck \& Co. 1989, p. 1207)

Flinn and Trojan

Polypropylene-Consistent with Merck (Flinn and Trojan 1981).

GRI

Polypropylene-Unsuitable for barium fluoride, acetate solvents, carbon tetrachloride, cyclohexane, gasoline, hydrogen peroxide, methyl chloride, concentrated nitric acid, nitric oxide, toluene, and trichloroethylene (GRI 1990).

\section{RyanHerco}

Polypropylene-Chemical resistance similar to that of polyethylene but suitable for higher temperatures. Polyethylene is resistant to aqueous solutions of acids, alkalies, and salts as well as many organic solvents. Unsuitable for concentrated oxidizing acids.

Specifically, polypropylene is unsuitable for methyl acetate chloride, nitric acid, concentrated sulphuric acid, trichloroethylene, and xylene (RyanHerco 1997).

Cole-Parmer

Polypropylene-Not recommended for aromatic hydrocarbons (Cole-Parmer 1985).

\subsection{RESULTS}

The chemical resistance of the polymers evaluated, polyester, PVC, polypropylene, and nylon, is similar. In general, these materials are particularly vulnerable to attack by strong oxidizers and aromatic hydrocarbons.

Strong oxidizers include peroxides $(0-0)$, chlorates $\left(\mathrm{ClO}_{3}\right)$, perchlorates $\left(\mathrm{ClO}_{4}\right)$, nitrates $\left(\mathrm{NO}_{3}\right)$, and permanganates $\left(\mathrm{MnO}_{4}\right)$. Of these ions, only nitrates appear on the list of materials in the waste tanks. However, nitrates appear only to be a problem at elevated temperatures for polypropylene, polyethylene, and PVC (Cole-Parmer 1985).

Aromatic hydrocarbons include benzenes and naphthalenes, which have been detected in the waste tanks. Specifically, phenol, nitrobenzene, phenanthrene, and naphthalene were 
identified. A specific concentration was not determined in the waste, so these may be a problem if they are present in high concentrations and contact the flexible receiver bag for an extended period. concern.

Nylon, which is used in the Cooley L18KU product, appears resistant to the chemicals of

\subsection{CONCLUSIONS AND RECOMMENDATIONS}

The selected materials are appropriate for the intended use in the flexible receiver bag. The materials are resistant to acids, alkalies, and salts.

The results indicate that nitrates and aromatic hydrocarbons are of particular concern for the materials used in each product evaluated. Nitrates only appear as a problem at elevated temperatures $\left(>49^{\circ} \mathrm{C}\left[120^{\circ} \mathrm{F}\right]\right)$, and it is assumed that the materials will not be used under these circumstances. Aromatic hydrocarbons are a potential problem, but the problem is mitigated by the operation and controls used to extract the LLCE from the waste tank and load it into the transport/storage container.

During removal of the LLCE, the accessible surfaces will be washed by a high-pressure spray wash, and little, if any, waste will remain on the exterior. This wash will be conducted as the LLCE is extracted form the tank in a vertical orientation. It is assumed that most of the waste that can drain from the interior of the LLCE while it is suspended will do so. However; some waste may be trapped in the LLCE and will not drain in this orientation. After the LLCE is extracted and in the flexible receiver bag, the LLCE will be lowered to a horizontal position. The LLCE will then be placed in the storage/disposal container. At this point, waste material trapped in the LLCE may drain into the flexible receiver bag.

The main purpose of the flexible receiver bag is to prevent the spread of contamination (radioactive and chemical), particularly while the LLCE is in a vertical position. Because of the wash and drain, it is very unlikely that a sufficient amount of waste could come in contact with the flexible receiver bag to compromise it. Therefore, the following assumptions support the conclusions.

- The tank waste will not be sustained at an elevated temperature (> $49^{\circ} \mathrm{C}\left[120^{\circ} \mathrm{F}\right]$ ) during the process of removing the LLCE.

- The LLCE will be pressure washed and allowed to drain in a vertical position to remove the majority of waste on the exterior before being lowered and placed in the disposal/storage container.

- Because the LLCE is placed on a skid when positioned in the LLCE container, the flexible receiver bag is not subjected to excessive abrasion during the operation.

- The flexible receiver bag is no longer required to provide the primary containment boundary after packaging in the LLCE container.

No particular brand of material is recommended because there may be other factors, such as ease of application, availability, and cost, that may affect the final selection. 
HNF-2893, Rev. 0

\subsection{REFERENCES}

Cole-Parmer, 1985, Cole-Parmer 1985-1986 Catalog, Cole-Parmer Instrument Company, Chicago, Illinois.

Cooley, 1995, L18KU PVC Coated Membrane: Product Specification (Minimum Values), Cooley Incorporated, Pawtucket, Rhode Island.

CRC, 1981, CRC Handbook of Chemistry and Physics, 62nd Edition 1981-1982, CRC Press, Boca Raton, Florida.

Flinn, R. A., and P. K. Trojan, 1981, Engineering Materials and Their Applications, Second Edition, Houghton Mifflin, Boston, Massachusetts.

GRI, 1990, GRI Standard Pump Catalog, Gorman-Rupp Industries, Bellville, Ohio.

Herculite, 1997, Material Safety Data Sheet, MSDS: Herculite (Herculite Products, Inc., Laboratory Report\}, Herculite Products, Inc., Emigsville, Pennsylvania.

Merck \& Co., Inc., 1989, The Merck Index, Eleventh Edition, Merck Publishing Group, Rahway, New Jersey.

Pig, Material Safety Data Sheet: Elephant Mat, New Pig Corporation, Tipton, Pennsylvania.

RyanHerco, 1997, RyanHerco Fluid Flow Solutions 1997 Product Guide, 22nd Edition, RyanHerco Fluid Fiow Solutions, Burbank California.

Veith, E. M., 1996, LLCE Burial Container HDPE Chemical Compatability, WHC-SD-WM-DA-226, Rev. O, Westinghouse Hanford Company, Richland, Washington. 
HNF-2893, Rev. 0

APPENDIX: HERCULITE PRODUCTS, INC. CHEMICAL RESISTANCE GUIDE

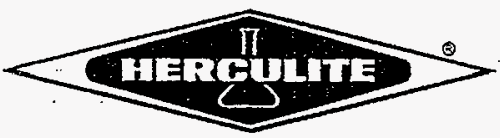

Technical information Bulletin TIB-1

CHEMICAL RESISTANCE GUIDE FOR

STANDARD HERCULITE BRAND FABRICS

All Herculite ${ }^{\otimes}$ brand fabrics, including Staph-Chek ${ }^{\otimes}$ hospital and institutional fabrics, possess exceptionally high strength and durability and are resistant to deterioration even under severe environmental stresses. Kerculite fabrics offer excellent chemical resistance and are resistant to inorganic salts, alkalies and weak aciós. They are also resistant to strong aciós, alcohols, aliphatic hydrocarbons and oils for short periods, depending on concentrations, temperatures and exposure times. The fabrics are not recommended for use with ketones and esters as these are considered solvents.

The resistance charts provided in this bulletin should serve as a general guide only. Recommendations at the listed temperatures are based on ideal conditions and all factors affecting chemical resistance must be taken into consideration. The user should pre-determine the suitability of a particular fabric style for their specific applieation.

In some applications involving exposure to acids, the fabric resistance will be improved one rating over that shown in the chart when using $14 \mathrm{oz}$. and heavier fabrics with the edges sealed by $\mathrm{CVV}^{\Theta}$ adhesive. This will prevent exposure of the reinforcernent to the acids. These applications are denoted by an asterisk (*).

Herculite Products, Inc. manufactures numerous other fabric styles for use where special exposure conditions exist. For example, Sanilite ${ }^{2}$ tabrics, which have FDA/USDA approval, ape designed for food contact applieations. Where increased oil resistance is needed, such as in oil booms and tank liners, Herculite Oil Resistant fâbrics are available.

Should there by any question in the user's mind, Herculite's Technical Service Department personnel will be pleased to advise the proper fabric selection for each application.

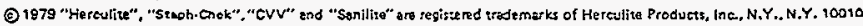


HNF-2893, Rev. 0

Page 2

CHEMICAL RESISTANCE GUIDE FOR STANDARD HERCULITE BRAND FABRICS

$R$ - Recommended $\quad L$ - Limited Exposure $\quad N R$ - Not Recommended

INORGANIC ACIDS AND ACID-MIXTURES

Aqua Regia

Arsenic Acid Solution

Boric Acid Solution .

Bromic Acid

Chromlc Acid (40\%)

Fluoboric Ació

Fluosilicic Acid

Hydrobromic Acid (20\%)

Hydrochloric Acid (35\%)

Hydrochloric Acid (10\%)

Hydrofluoric Acid (48\%)

Hyórofluoric Acid (10\%)

Nitric Acid (68\%)

Nitric Acid (25\%)

Nitric Acid $(10 \%)$

Oleum

Perchloric Acid (70\%)

Perchioric Acid (10\%)

Phosphoric Acld (75\%)

Phosphoric Acid (10\%)

Selenic Acid

Sulfuric Acid (89\%)

Sulfuric Acid (50\%)

Sulfuric Acid (10\%)

\section{ALKALIES AND BASES}

Aluminum Hydroxide

Ammonium Hydroxide (28\%)

Ammonium Hydroxice (10\%)

Barium Hydroxide

Calcium Hydroxide

\begin{tabular}{|c|c|c|c|c|}
\hline $72^{\circ} \mathrm{F}$ & $150^{\circ} \mathrm{F}$ & ALKALIES AND BASES ICO & $72^{\circ} \mathrm{F}$ & $150^{\circ} \mathrm{F}$ \\
\hline NR & NR & Magnesium Hyoroxide & R & $R$ \\
\hline R & NR & Potassium Hydroxide (50\%) & $\mathbf{R}$ & NR \\
\hline 月 & 8 & Potassium Hydroxide (10\%) & R & R \\
\hline$R$ & NR & Sodium Hyoroxide $(50 \%)$ & 8 & NR \\
\hline$L^{*}$ & $N R^{*}$ & Sodium Hydroxide $(10 \%)$ & R & $R$ \\
\hline $\begin{array}{l}L^{*} \\
L^{*}\end{array}$ & $\begin{array}{l}L^{*} \\
L^{*}\end{array}$ & INORGANIC SALTS AND C & UNDS & \\
\hline$L^{*}$ & NR & Aluminum Chloride & $R$ & R \\
\hline$L^{*}$ & $N R$ & Aluminum Fluoride & R & NR \\
\hline$R$ & $L^{*}$ & Aluminum Sulfate & R & 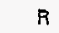 \\
\hline & & Ammonia (Liquid) & NR & NR \\
\hline$L$ & NR & Ammonium Bifluoride & $R$ & $R$ \\
\hline R & NR & & & \\
\hline L & NR & Ammonium Chloride & R & $\mathbf{R}$ \\
\hline R & NR & Ammonium Fluoride $(25 \%)$ & R & $R$ \\
\hline$R$ & $L^{*}$ & Ammonium Nitrate & R & $R$ \\
\hline & & Ammonium Sulfate & $\mathbf{R}$ & $\pi$ \\
\hline NR & NR & Ammonium Sulfide & R & $R$ \\
\hline NR. & NR & & & \\
\hline 8 & NR & Antimony Trichloride & $\mathbf{R}$ & $R$ \\
\hline$R$ & $\mathrm{NR}$ & Barium Chloride & R & $R$ \\
\hline R & R & Barium Sulfate & $\mathbf{R}$ & $R$ \\
\hline & & Barium Sulfide & $\mathbf{R}$ & NR \\
\hline R & NR & Bromine (Liquid) & NR & NR \\
\hline$L$ & NR & $\cdot$ & & \\
\hline$L^{*}$ & $N R$ & Bromine (Water) & $R$ & NR \\
\hline$R$ & $R$ & Calcium Chloride & $R$ & $\mathbf{R}$ \\
\hline & & Calcium Hypochlorite (10\%) & $L^{*}$ & NR \\
\hline & & Celcium Hypochlorite (1\%) & $\mathbf{R}$ & L \\
\hline & & Calcium Nitrate & R & $R$ \\
\hline R & $R$ & & & \\
\hline$R$ & NR & Calcium Sulfate & R & $R$ \\
\hline R & $R$ & Chlorine, Water & R & $R$ \\
\hline$R$ & R & Chlorine Dioxide $(15 \%)$ & $R$ & NR \\
\hline R & $R$ & Copper Nitrate & R & $\mathbf{R}$ \\
\hline
\end{tabular}


HNF-2893, Rev. 0

Page 3

CHEMICAL RESISTANCE GUIOE FOR STANDARD HERCULITE BRAND FABRICS

$R$-Recommended $L$-Limited Exposure $\quad N R$ - Not Recommended

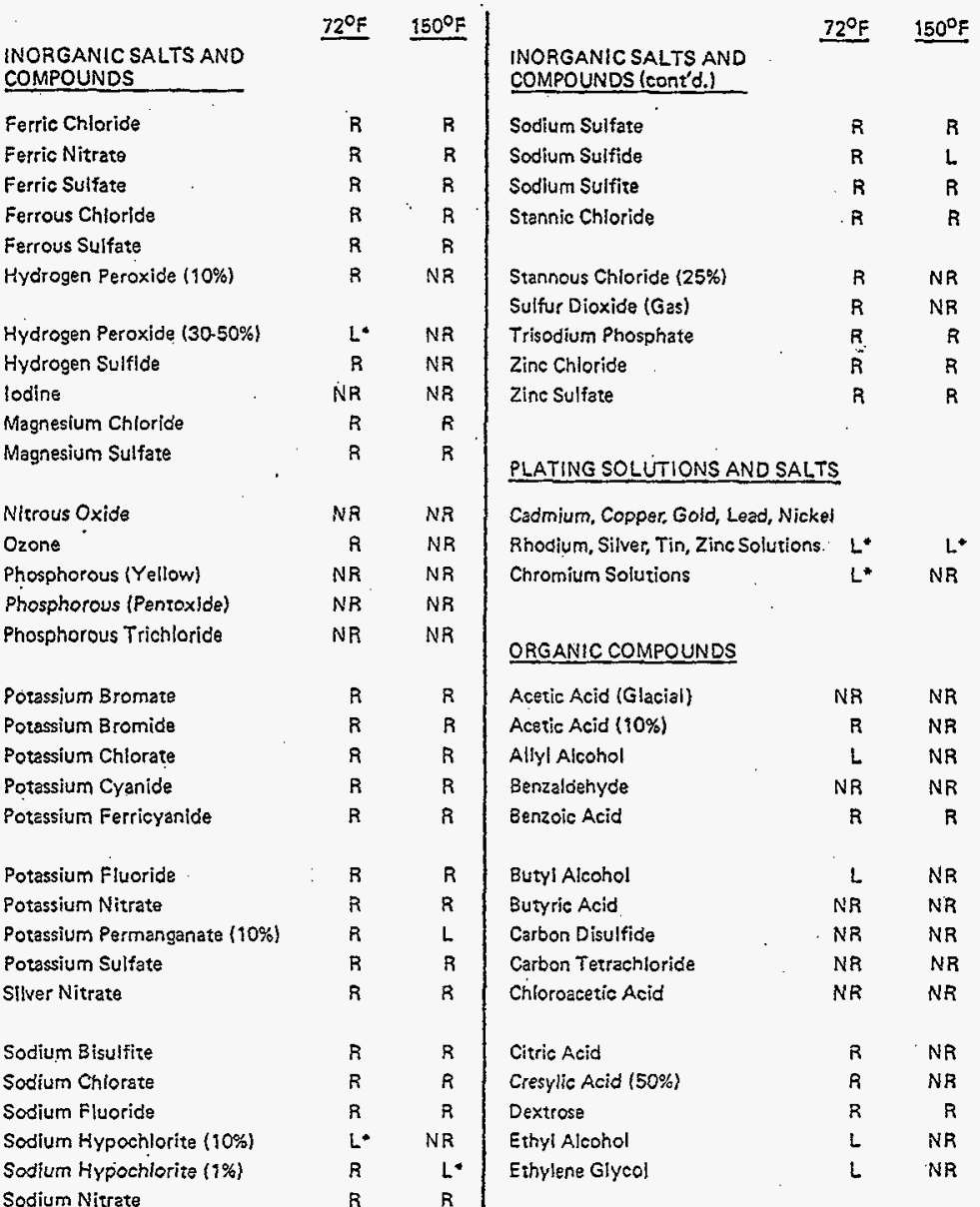




\section{CHEMICAL RESISTANCE GUIDE FOR STANDARD HERCULITE BRAND FABRICS}

$$
R \text {-Recommended } L \text { - Limited Exposure NR-Not Recommended }
$$

\begin{tabular}{|c|c|c|c|c|c|}
\hline \multirow[b]{2}{*}{ ORGANIC COMPOUNDS } & $72^{\circ} \mathrm{F}$ & $150^{\circ} \mathrm{F}$ & \multirow{2}{*}{\multicolumn{2}{|c|}{ MISCELLANEOUS COMPOUNDS $\stackrel{72^{\circ} \mathrm{F}}{ }$}} & $150^{\circ} \mathrm{F}$ \\
\hline & & & & & \\
\hline Fatty Acid's & $L$ & NR & Alums & R & NR \\
\hline Formaldehyde & $L$ & NR & Beer & $R$ & - \\
\hline Formic Acid & $R$ & $\mathbf{R}$ & Beet (Sugar Liquor) & $R$ & R \\
\hline Glucose & $R$ & R & Brine & $R$ & $\mathbf{L}$ \\
\hline Glycerine & $\mathbf{R}$ & NR & Bleach (16\% Chlorine) & $L^{*}$ & $N R$. \\
\hline Glycol & $L$ & NR & Castor Oil & $\mathbf{L}$ & $\mathrm{l}$. \\
\hline Kerosens & $L$ & NR & Corn Syrup & $\mathbf{R}$ & NR \\
\hline Lactic Acid $(28 \%)$ & $R$ & NR & Cottonseed Oil & $\mathbf{L}$ & NR \\
\hline Maleic Acid & $L$ & NR & Fruit Pulp \& Juice & $\mathrm{R}$ & $R$ \\
\hline Methyl Alcohol & $\mathrm{L}$ & NR & Gasoline & L & NR \\
\hline Dleic Acid & $L$ & NR & Milk & $R$ & $\mathbf{R}$ \\
\hline Oxalic Acid & $L$ & NR & Mineral Oil & $L$ & NR \\
\hline Phenol & L & NR & Molasses & $\mathbf{R}$ & $R$ \\
\hline Picric Acid & $L$ & NR & Photographic Chemicals & $R$ & $R$ \\
\hline Propyl Alcohol' & $L$ & NR & Tanning Liquors & $L$ & $\dot{N} R$ \\
\hline Stearic Acid & $L$ & $N R$ & Water (Demineralized) & $R$ & $R$ \\
\hline Tannic Acid & $\mathbf{R}$ & NR & Water \{Sea\} & $R$ & $R$ \\
\hline Tartaric Acid & $R$ & NR & Wines & R & - \\
\hline Tetraeshyl Lead & $N R$ & $\mathrm{NR}$ & & & \\
\hline Turpentine & $\mathrm{L}$ & NR & & & \\
\hline Urea & $\mathbf{R}$ & R & & & \\
\hline
\end{tabular}

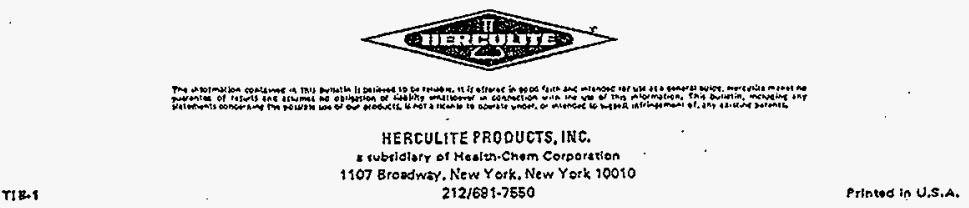




\section{DISTRIBUTION SHEET}

\begin{tabular}{|c|c|c|c|c|c|}
\hline \multirow{2}{*}{$\begin{array}{l}\text { To } \\
\text { Distribution }\end{array}$} & \multirow{2}{*}{\multicolumn{3}{|c|}{$\begin{array}{l}\text { From } \\
\text { Packaging Engineering }\end{array}$}} & \multicolumn{2}{|l|}{ Page 1 of 1} \\
\hline & & & & \multicolumn{2}{|c|}{ Date June 16,1998} \\
\hline \multirow{2}{*}{\multicolumn{4}{|c|}{$\begin{array}{l}\text { Project Title/Work Order } \\
\text { Chemical Compatibilit } \\
\text { Elephant Mat With Han }\end{array}$}} & \multirow{2}{*}{\multicolumn{2}{|c|}{$\begin{array}{ll}\text { EDT No. } & 622367 \\
\text { ECN No. } & N / A\end{array}$}} \\
\hline & & & & & \\
\hline \multicolumn{2}{|l|}{ Name } & $\begin{array}{l}\text { Text } \\
\text { With All } \\
\text { Attach. }\end{array}$ & Text Only & $\begin{array}{l}\text { Attach./ } \\
\text { Appendix } \\
\text { Only }\end{array}$ & $\begin{array}{l}\text { EDT/ECN } \\
\text { Only }\end{array}$ \\
\hline $\begin{array}{l}\text { D. W. Crass } \\
\text { J. G. Field } \\
\text { D. E. Legare } \\
\text { W. A. McCormick } \\
\text { J. G. McFadden } \\
\text { M. E. McKinney } \\
\text { J. E. Mercado } \\
\text { Central Fi\}es } \\
\text { HNF-2893 File } \\
\text { Work Control (D. Kelly) }\end{array}$ & $\begin{array}{l}\text { R3-47 } \\
H 1-15 \\
\text { R3-47 } \\
\text { R3-47 } \\
H 1-15 \\
\text { S2-48 } \\
H 1-15 \\
\text { B }-07 \\
H 1-15 \\
H 1-15\end{array}$ & $\begin{array}{l}X \\
X \\
X \\
X \\
X \\
X \\
X \\
X \\
X\end{array}$ & & , & $X$ \\
\hline
\end{tabular}

